\title{
Learning in practice
}

\section{Reform of undergraduate medical teaching in the United Kingdom: a triumph of evangelism over common sense}

\author{
Gareth Williams, Alice Lau \\ There is an urgent need to test whether the current reforms in training of doctors are the right \\ answer to the shortcomings of traditional training
}

Faculty of Medicine and Dentistry, University of Bristol, Bristol BS8 1TH Gareth Williams dean

Alice Lau fourth year medical student

Correspondence to: G Williams Gareth.Williams@ bris.ac.uk

BMJ 2004;329:92-4
The past decade has seen concerted attempts to revolutionise undergraduate medical training in the United Kingdom. Advocates for change have claimed that traditional teaching is old fashioned and too detailed and produces doctors with poor interpersonal skills (box). Key reforms, endorsed by the UK General Medical Council (GMC), included the deliberate reduction of factual knowledge and the replacement of didactic teaching with problem based learning (PBL) directed by the students themselves. ${ }^{1}$ About a third of UK medical schools have now embraced these principles.

This strategy is entirely untested in UK medical students, and no evidence exists that it will produce better doctors. Here, we argue that the "new" ideology may actually damage medical training in this country and that educational reform is being driven by enthusiasm for change rather than by rational responses to the shortcomings of traditional curriculums.

\section{What do doctors really need to know?}

It is true that practising doctors do not use large tracts of the knowledge they acquired as students. This redundancy is particularly striking in the basic medical sciences (for example, anatomy, biochemistry, physiology, pathology, and pharmacology); why should undergraduates learn biochemical pathways that even consultants in metabolic medicine do not need for their everyday work? The desire to abolish so called information overload prompted the GMC to recommend that "factual information must be kept to the essential minimum that students need at this stage of medical education." Careful pruning of superfluous detail carries obvious benefits, but we believe that the GMC's advice has in some cases been followed to potentially dangerous extremes.

Some medical schools have now largely abandoned formal teaching of basic medical sciences, leaving students to explore these crucial areas alone or through the poorly suited approach of PBL. No evidence exists that this approach will produce better doctors; indeed, new doctors will now risk not knowing enough to practise effectively and safely. The assault on information overload has also eroded clinical experi-
Principles underlying reform of undergraduate medical core curriculum

- Reduce information overload-stop students learning unnecessary detail

- Improve on traditional teaching methods-replace traditional "didactic" teaching with problem based learning

- Give students control over their own learning-let students determine what they need to know (and what they wish to be examined in)

- Make undergraduate training a platform for lifelong learning-becoming a doctor is only the first stage of continuing medical education throughout the career

- Improve doctors' interpersonal skills-train students to be empathic and relate better to their patients and their problems

ence. Increasingly, teaching focuses on common "core" diseases (to the detriment of people unlucky enough to have "non-core" conditions); time spent in specialties such as dermatology and ophthalmology is also being curtailed. The void created by cutting factual teaching has been filled partly by the expansion of other activities, such as communication skills and material chosen by the students themselves. The GMC recommends that students should select $30 \%$ of the undergraduate course and that up to $10 \%$ of the course need not relate to medical subjects. ${ }^{1}$ This diversification may help to produce well rounded doctors but may not represent the best use of time when the core business of acquiring functional medical knowledge is already under threat.

A further risk is that disciplines to which students are no longer exposed will find it harder to attract potential recruits. Likely casualties include pathology, anatomy, and microbiology, which are already facing major problems in filling posts.

Becoming a proficient doctor has always demanded hard work; it is unacceptable to leave out large parts of traditional training simply because there is a lot to learn. Some students may work harder on their own to compensate for deficiencies in the curriculum, ${ }^{2}$ but it may be naive to assume that the 


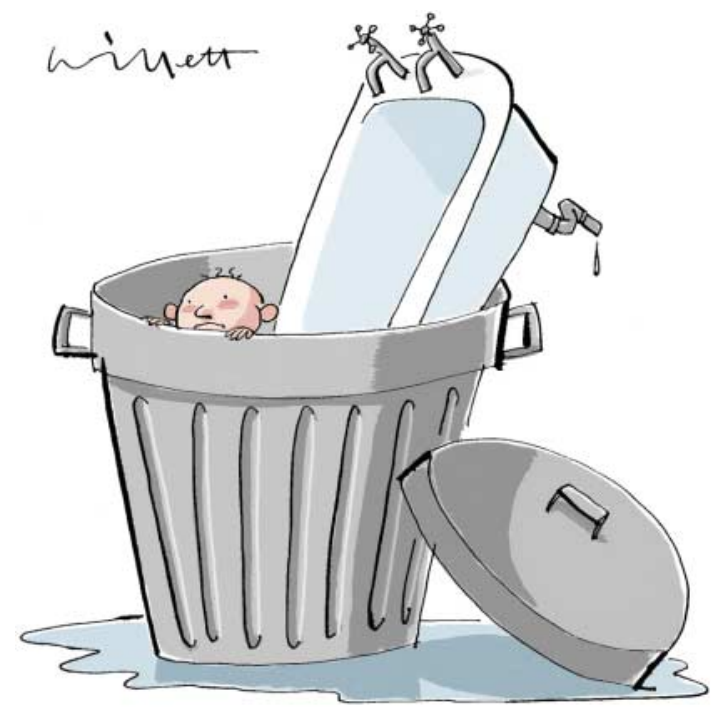

18-19 year old entrants to UK medical schools are mature enough to do this. ${ }^{3}$

\section{How should students learn medicine?}

Reformers dismiss didactic teaching-for example, lectures and tutorials-as outdated spoonfeeding that stifles creative thinking and keeps the student inferior to the teacher. PBL has been promoted as a liberating and "humane" alternative. ${ }^{2} \mathrm{PBL}$ is supposed to operate through a combination of group discussion and individual research, in which the students decide their own learning objectives, strategy, and pace. A facilitator, who is not intended to teach, ${ }^{4}$ is relatively passive, merely guiding the sessions; moreover, many PBL facilitators have no specialist knowledge (some have no medical background at all).

PBL can undoubtedly encourage useful discussion among highly motivated students who already understand the factual background. However, with a dysfunctional group or an ineffective facilitator, or both, PBL readily degenerates into a near-Brownian waste of time and energy. It is also an illogical and inefficient way to acquire basic knowledge. Can the average UK school leaver (aided perhaps by a historian) really be expected to identify what a doctor needs to know about biochemistry-and without wasting time or becoming overloaded with redundant information? Finally, PBL may be more humane, but it also deprives students of contact with inspirational teachers.

Medical PBL was pioneered at flagship institutions such as McGill and McMaster Universities in Canada. These take only the top few per cent of applicants, all of whom already have a primary degree; these elite students could probably learn medicine under the worst conditions, and it is a major leap of faith to assume that most medical school entrants in Britain will be as mature or as motivated. Interestingly, despite their impressive credentials, McMaster graduates feel no better prepared than their peers do for postgraduate training. ${ }^{5}$ Moreover, a meta-analysis shows that, overall, PBL does not produce doctors with better factual or clinical knowledge than those from traditional curriculums. ${ }^{6}$ Enthusiasm for PBL, and the undue haste with which it is being introduced, is therefore hard to explain-especially as its suitability to UK medical students has not been tested.

\section{"Dumbed down" or liberated problem solvers?}

Debate has been lively about whether "new" curriculums will actually produce better doctors than the old curriculums. Predictably, traditionalists complain that medical knowledge is being "dumbed down"; equally predictably, reformers claim that liberating students from the drudgery of learning facts will improve their problem solving skills. ${ }^{7}$ The jury must remain out until the two have been adequately compared, although the available evidence indicates that factual knowledge is the essential base for developing the problem solving skills of a good clinician. ${ }^{8}$

\section{What is driving educational reform in medicine?}

In the age of evidence based medicine, it is strange that such fundamental changes, crucial to the future of the profession, are being pushed through in the absence of any proof that they will improve medical training.

One factor may be fear of the GMC, which sits in judgment on undergraduate medical training and ultimately has the power to close medical schools that it finds wanting. The GMC's vision, laid out in Tomorrow's Doctors (published first in 1993, revised in 2002), ${ }^{1}$ has both catalysed and legitimised the key reforms. The core of the revised Tomorrow's Doctors is a poorly structured and rather repetitive list of 96 items that are supposed to define a good doctor. The list is dominated by advice on how doctors should interact with their patients and colleagues, possibly as a reaction to various high profile doctors who have exemplified arrogance, indifference, dishonesty, and evil. Bizarrely, only six items describe the unique qualities that distinguish a doctor from other healthcare workers. Even if it does not reflect the GMC's priorities, the ordering of the list is idiosyncratic; the doctor's particular skills are not explicitly mentioned until item 19, while the preceding item tells doctors that they have to know about complementary medicine.

\section{Conclusions}

Diversity in the approaches to medical training is to be welcomed, but only if the end result is doctors who are truly fit for the purpose. Reform of medical training has now acquired immense momentum in the United Kingdom. The absence of any evidence that new ideologies will produce better doctors than do traditional curriculums forces us to conclude that these reforms are being propelled more by evangelical zeal than by rationale. Despite their faults, traditional curriculums have managed to produce humane and conscientious doctors with a solid knowledge base that equips them for a career in a broad spectrum of medicine. By contrast, there has been no test in the UK of the ability of the now fashionable "minimalist" approach to train doctors who are adaptable and skilled enough to work in all specialties. By pushing these changes through with undue haste, the reformers 


\section{Summary points}

Traditional medical training produces doctors with a sound knowledge base that allows them to practise across a broad spectrum of medicine

Reformers aim to cut the student's factual knowledge base, while replacing traditional teaching methods with student led and problem based approaches

There is no evidence that the "new" strategies will produce better doctors, and a risk that students with inadequate knowledge will become poor clinicians

A rigorous comparison of "traditional" versus "new" curriculums is urgently needed to determine the best strategy for training doctors

have effectively thrown out the bath water, baby, and much of the plumbing.

Reformers always have a duty to prove that their proposals are necessary, sound, and practicable and that they will genuinely improve on whatever went before. We believe that the current reforms are a creaking bandwagon whose wheels will eventually drop off-with dire consequences for the future of the profession and our patients. This view can be convincingly rejected only by rigorous comparison of the doctors produced by new and traditional curriculums. The stage is ideally set to test whether the current reforms are the right answer to the shortcomings of traditional medical training. Any damage caused by a patchy knowledge base might not become apparent until doctors acquire relative seniority ${ }^{8}$; it follows that the comparison should begin without delay and should follow doctors as they progress through their career.

The training of doctors is too important an activity for bold experiments to be conducted without discovering what really happens. The GMC should now seize the initiative in driving forward a comprehensive review of "old" versus "new."

Contributors and sources: GW wrote the first draft of the paper, which was amended and polished by AL. Both authors are the products of essentially traditional undergraduate training, spanning a period of three decades or so. Some of this material was used by GW and AL in a debate on undergraduate medical education held in Liverpool in May 2003 (where their motion was heavily defeated). The article reflects the authors' personal views. Funding: None.

Competing interests: None declared.

1 General Medical Council. Tomorrow's doctors. Recommendations on undergraduate medical education. London: GMC, 2002.

Norman G. Research in medical education: three decades of progress. BMJ 2002;324:1560-2

3 Misch DA. Andragogy and medical education: are medical students internally motivated to learn? Adv Health Ser Educ 2002;7:153-60.

4 Wood DF. ABC of learning and teaching in medicine: problem based learning. $B M J 2002$.

5 Woodward CA, Ferrier BM. The content of the medical curriculum at McMaster University: graduates' evaluation of their preparation for postgraduate training. Med Educ 1983;17:54-60.

6 Vernon DTA, Blake RL. Does problem-based learning work? A meta-analysis of evaluate research. Acad Med 1993;68:550-63.

7 Chastonay P, Brenner E, Peel S, Guilbert J-J. The need for more efficiency and relevance in medical education. Med Educ 1996;30:235-8.

Barrows HS, Norman GR, Neufeld VR, Feightner JW. The clinical reasoning process of randomly selected physicians in general medical practice. Clin Invest Med 1982;5:49-56.

(Accepted 28 January 2004)

\section{Seeing is believing}

The popular history of medicine largely consists of stories of brutal procedures carried out at great risk to the patients in the hope of curing disease or preventing death. Some would say that such brutality continues in the 21 st century.

I was recently told the shocking story of what had happened to a friend of mine during the birth of her first child. She had hoped to have the baby at home, but after prolonged labour it became clear that an emergency caesarean section was indicated. My friend was rushed to hospital in considerable pain, along with her worried husband, and was taken directly to theatre. It was clear that the baby needed to be delivered immediately, and at this point the anaesthetist apparently did something quite extraordinary.

He suggested to the husband that he left the room for a moment, because he "probably wouldn't want to see this," and then throttled my friend until she lost consciousness, so that the obstetrician could begin the operation. The husband witnessed this happening as he was leaving the room, and the memory of it has caused him considerable distress.

I was amazed by this story and tried to find out whether this could really have happened. After speaking to a surgical colleague, a more plausible explanation emerged. Apparently, when somebody undergoes an emergency general anaesthetic and has not fasted beforehand, it is good practice to apply manual pressure on the cricoid cartilage during induction to prevent aspiration of stomach contents. Presumably the husband had witnessed this being done, shortly after his wife had been anaesthetised in the normal way. It is quite understandable that a layperson, especially in a highly anxious state, might think it feasible that the quickest way to render someone unconscious would be to strangle her. After all, in an emergency, drastic action is often necessary.

There must be lessons to be learnt from this story, but I am not sure what. Should the anaesthetist have explained to the husband the purpose of everything that he was doing? Could the obstetric team have asked the husband afterwards if he had seen anything upsetting? In an ideal world, perhaps these things could have been done, but the anaesthetist had done nothing unusual (let alone wrong) and was acting in an emergency. Moreover, how could anybody be expected to know that the husband had seen and misinterpreted something in such a dramatic way unless he said so?

Perhaps the real lessons are these. Firstly, remember that doctors still perform gruesome procedures on their patients in the name of medicine (just ask any orthopaedic surgeon). The fact that they may be accepted practice and done for all the right reasons does not mean that they are not brutal and potentially dangerous. Secondly, such procedures must seem horrifying to anybody who is not used to seeing them, especially when they are carried out on loved ones. Finally, beware the subjective nature of reality and remember that what our patients witness is not always the same as what they see.

Ashley Rule specialist registrar in adult psychiatry, Royal London Hospital, London 